\section{International Journal of Medical Research and Review}

\title{
A Study on the correlation between platelet indices and severity score in acute ischemic stroke
}

\author{
Govind D. ${ }^{1}$, Malleswara Rao M. ${ }^{2 *}$, Sudheer K. ${ }^{3}$ \\ DOI: https://doi.org/10.17511/ijmrr.2020.i05.04 \\ 1 Dasari Govind, Assistant Professor, Department of Medicine, Great Eastern Medical School and Hospital, Srikakulam, Andhra Pradesh, \\ India. \\ 2* Mallipeddi Malleswara Rao, Associate Professor, Department of Medicine, Great Eastern Medical School and Hospital, Srikakulam, Andhra \\ Pradesh, India. \\ 3 Sudheer K., Professor, Department of Medicine, Great Eastern Medical School and Hospital, Srikakulam, Andhra Pradesh, India.
}

Background: Acute ischemic stroke results from the sudden loss of blood circulation to an area of cerebral hemispheres leading to irreversible brain injury and neurological deficits persisting for more than 24 hours or until death. It accounts for $80-87 \%$ of all strokes. The present study aimed to find the association between various hematological indices such as Mean platelet Volume (MPV), Platelet Distribution Width (PDW), Platelet to Lymphocyte ratio (PLR), and National Institute of Health Stroke Scale (NIHSS). Methods: It was a prospective study done at the Department of Medicine at Great Eastern Medical School and Hospital in which 80 patients with Acute Ischemic stroke were divided into two groups basing on the NIHSS score. Proper Exclusion criteria were carried out and the patients' blood samples were taken. Various Platelet and hematological indices were measured and statistical analysis was done using SPSS Software. Results: There is a positive correlation between PLR and NIHSS scores. It is a statistically significant association. But there is no statistical significance between Platelet indices and NIHSS score. Conclusion: Being Low cost and easy to measure the nature of PLR, these indices can be used in the prediction of the prognosis in Acute Ischemic Stroke Patients.

Keywords: Platelet indices, acute ischemic stroke, stroke, Mean platelet volume, Platelet Distribution Width, Platelet to Lymphocyte ratio, National Institute of Health Stroke Scale

\section{Corresponding Author}

Mallipeddi Malleswara Rao, Associate Professor, Department of Medicine, Great Eastern Medical School and Hospital, Srikakulam, Andhra Pradesh, India.

Email: govinddr79@gmail.com

\section{How to Cite this Article}

Govind D, Rao MM, Sudheer K. A Study on the correlation between platelet indices and severity score in acute ischemic stroke. Int J Med Res Rev. 2020;8(5):363-368.

Available From

https://ijmrr.medresearch.in/index.php/ijmrr/article/ view/1220
To Browse

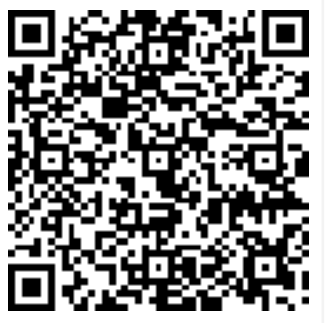

Manuscript Received 2020-10-16

Conflict of Interest No
Review Round 1 2020-10-24

Funding Nil

Review Round 2
2020-10-27
Ethical Approval
Yes

Review Round 2 Yes
Review Round 3

Plagiarism X-checker $6 \%$
Accepted 2020-10-30

Note

(c) 2020 by Dasari Govind, Mallipeddi Malleswara Rao, Sudheer K. and Published by Siddharth Health Research and Social Welfare Society. This is an Open Access article licensed under a Creative Commons Attribution 4.0 International License ttps://creativecommons.org/licenses/by/4.0/ unported [CC BY 4.0]. 


\section{Introduction}

Acute ischemic stroke is not only a severe disabling cerebrovascular event [1] but also has a great impact on a patient's life and socioeconomic burden [2]. Although it can be prevented by controlling relevant risk factors [3], its prevalence and incidence remain rising with the aging and atherosclerotic process [4]. It is the comment cause of mortality after coronary artery disease and the commonest cause of chronic adult disability [5].

Acute ischemic stroke results from the sudden loss of blood circulation to an area of cerebral hemispheres leading to irreversible brain injury and neurological deficits persisting for more than 24 hours or until death. It accounts for $80-87 \%$ of all strokes [6].

Platelet activation and aggregation are critical in the pathogenesis of acute ischemic stroke. There exist parameters to monitor platelets and their changes, namely: Mean Platelet Volume (MPV), Mean Platelet Count (MPC), Plateletcrit (PCT), and Platelet Distribution Width (PDW) [7]. Together, these are called Platelet indices. Studies have shown that these indices are good indicators of thrombotic states [8].

MPV is a commonly used biomarker of platelet function and activation [9]. Increased MPV has been associated with greater in vitro aggregation in response to ADP and Collagen thereby associated with Myocardial Infraction, Transient Ischemic Attacks, and Ischemic Stroke $[10,11,12,13,14]$. PDW represents variation in platelet size. Larger PDW also indicates a prothrombotic status [15]. These indices are cost-effective and routinely available.

Since Acute Ischemic stroke is an inflammatory event where the ischemic tissue releases chemokines and cytokines, and recruit peripheral circulating leucocytes [16]. Lymphocytes also infiltrate the ischemic tissues and mediate inflammatory responses [16]. Among the leucocytes, neutrophils were found to be an important mediator and early neutrophilia was found to be associated with larger stroke volumes and poor prognosis [17].

In recent years, the platelet to lymphocyte ratio (PLR) has emerged as a well-accepted biomarker for the assessment of overall inflammatory status. These are simple and cost-effective biomarkers [18].
Elevated levels of PLR are related to oxidative stress and increased cytokine production in patients [19]. The PLR has been used to predict poor prognoses, the rate of insufficient recanalization, and the size of the infarcted area following stroke [20].

\section{Aim of the Study}

Our present study aims to investigate the relationship between platelet indices and stroke severity scores in acute ischemic stroke.

\section{Materials and Methods}

The study is conducted in the Department of General Medicine at Great Eastern Medical College and Hospital, Andhra Pradesh after getting approval from the institutional ethics committee.

Duration of Study: September 2018 to July 2019

Sample size: 80 consecutive subjects with ischemic stroke admitted to the Department of General Medicine.

Type of study: Prospective Study

Method of collection of Data: After obtaining consent, the patients were subjected to a detailed history, clinical examination, and investigations as per the proforma. Each patient was assessed and an NIHSS score was assigned to them.

\section{Inclusion Criteria:}

01 . Age more than 18 years

02. All patients with acute ischemic stroke confirmed by history, neurological examination, and imaging modalities.

03. Patients who are willing to give written informed consent.

\section{Exclusion Criteria:}

01. Patients with hemorrhagic stroke and a previous attack of ischemic stroke.

02. Patients with comorbid medical illness likely to interfere with platelet function or morphology like chronic kidney disease, heart bypass surgery, chronic liver disease, leukemia, active infection without infection, and autoimmune diseases.

03. Patients receiving medication likely to interfere with platelet morphology or function like aspirin and other NSAIDs, antihistamines, and some antibiotics. 
04. Patients presenting $48 \mathrm{hrs}$. after the onset of neurological symptoms.

For the measurement of indices, a blood sample was collected from the antecubital vein using a $5 \mathrm{cc}$ syringe and transferred to an EDTA Test tube and analyzed in an Automated cell counter system within 90 min after collection.

Statistical Analysis: The Data obtained from the hematological investigations was entered in Microsoft Excel and Statistical Package for Social Sciences- SPSS for window version 17 software used for the statistical analysis. The results for each parameter for discrete data and averaged for each parameter were presented in tables.

\section{Results}

In the present study, out of 80 patients, 64 were males and 16 were females. Most of the patients were in the 50-70 years age group.

Around $62.5 \%$ were in the $45-60$ years age group, $26.25 \%$ were in the $61-70$ years age group. $6.25 \%$ were in the $<45$ years age group and $5 \%$ were in the $>70$ years age group (Table 1 ).

Table-1: Distribution of patients in different age groups.

\begin{tabular}{|l|l|l|l|}
\hline \multicolumn{1}{|c|}{ Age Group } & \multicolumn{1}{c|}{ Male } & \multicolumn{1}{c|}{ Female } & \multicolumn{1}{c|}{$\%$} \\
\hline$<45$ Years & 3 & 2 & 6.25 \\
\hline $45-60$ Years & 42 & 8 & 62.5 \\
\hline $61-70$ Years & 16 & 5 & 26.25 \\
\hline$>70$ & 3 & 1 & 5 \\
\hline Total & 64 & 16 & 80 \\
\hline
\end{tabular}

Among the risk factors, the order of prevalence is Hypertension > Diabetes Mellitus > Smoking > Alcoholism > Dyslipidaemia. It is depicted in Table 2.

Table-2: Presenting risk factor distribution in the study population.

\begin{tabular}{|l|l|l|l|l|l|l|}
\hline \multirow{2}{*}{ Risk Factor } & \multicolumn{2}{|c|}{ Male $(\mathbf{n = 6 4})$} & \multicolumn{2}{c|}{ Female $(\mathbf{n = 1 6})$} & \multicolumn{2}{c|}{ Total $(\mathbf{n = 8 0})$} \\
\cline { 2 - 8 } & Number & $\%$ & Number & $\%$ & Number & $\%$ \\
\hline Hypertension & 56 & 87.5 & 12 & 75 & 68 & 85 \\
\hline Diabetes Mellitus & 52 & 81.2 & 10 & 62.5 & 62 & 77.5 \\
\hline Dyslipidaemia & 20 & 31.2 & 7 & 43.7 & 27 & 33.7 \\
\hline Smoking & 58 & 90.6 & 3 & 18.7 & 61 & 76.2 \\
\hline Alcoholism & 56 & 87.5 & 0 & 0 & 56 & 70 \\
\hline
\end{tabular}

In the present study, these 80 patients are divided into two groups basing on the National Institute of Health Stroke Scale (NIHSS) score.
The set of patients whose NIHSS score is less than 6 is taken as 'Group 1' and the set of patients whose NIHSS score is more than or equal to 6 is taken as 'Group 2'. The number of patients under 'Group 1' is 46 and those under 'Group 2' are 34.

Table-3: Laboratory Data of Group 1 and Group 2 along with NIHSS score.

\begin{tabular}{|l|l|l|l|}
\hline \multicolumn{1}{|c|}{ Variables } & \multicolumn{1}{|c|}{$\begin{array}{c}\text { Group 1 } \\
(\mathbf{n = 4 6})\end{array}$} & \multicolumn{1}{|c|}{$\begin{array}{c}\text { Group 2 } \\
(\mathbf{n = 3 4 )}\end{array}$} & Total $(\mathbf{n = 1 0 0 )}$ \\
\hline $\begin{array}{l}\text { Leukocyte } \\
\text { count/1000/L }\end{array}$ & $8.58 \pm 2.60$ & $8.34 \pm 2.42$ & $8.94 \pm 2.92$ \\
\hline Neutrophil/1000/L & $\begin{array}{l}4.87(3.94- \\
6.62)\end{array}$ & $\begin{array}{l}5.69(4.38- \\
7.21)\end{array}$ & $\begin{array}{l}5.84(3.82- \\
7.64)\end{array}$ \\
\hline Lymphocyte/1000/L & $2.20(1.88-$ & $1.71(1.72-$ & $1.38(1.38-$ \\
& $2.47)$ & $2.22)$ & $2.63)$ \\
\hline Platelet count/1000/L & $228.64 \pm 77.82$ & $209.72 \pm 56.42$ & $215.82 \pm 68.62$ \\
\hline Stroke Severity Score & $2.96 \pm 1.81$ & $15.12 \pm 8.02$ & $8.78 \pm 8.24$ \\
\hline Average NIHSS &
\end{tabular}

Data Expressed is Means \pm standard deviation, median (1st quantile to 3rd quantile)

In the present study, the laboratory findings showed that Leukocyte count, Neutrophil, Lymphocyte, and Platelet count doesn't differentiate between these two groups of patients (Table 3 ).

Table 4. Platelet indices in group 1 and group 2.

\begin{tabular}{|l|c|c|}
\hline \multicolumn{1}{|c|}{ Variable } & Group 1 & Group 2 \\
\hline Mean Platelet Volume (MPV) & $12.48 \pm 1.46$ & $12.87 \pm 1.23$ \\
\hline Platelet Distribution Width (PDW) & $18.42 \pm 2.86$ & $18.48 \pm 2.92$ \\
\hline
\end{tabular}

Data Expressed is Means \pm standard deviation

In the present study, the platelet indices don't differ significantly between these two groups of patients (Table 4).

But Platelet-to-Lymphocyte ratio is significantly more in Group 2 thereby indicating a positive correlation of PLR with a high Stroke Severity Score and poor prognosis (Table 5).

Table-5: PLR in group 1 and group 2.

\begin{tabular}{|c|c|c|}
\hline Variables & Group 1 & Group 2 \\
\hline Platelet-to-Lymphocyte Ratio (PLR) & 97.8 (78.6-122.6) & 134.5 (94.6-178.7) \\
\hline
\end{tabular}

\section{Discussion}

The study was conducted to investigate the correlation between various platelet indices concerning the Stroke Severity Score. The study mainly focused on Platelet indices and Platelet-toLymphocyte Ratio with NIHSS Score. 
When assessing the risk factors for stroke in these patients, the present study showed that Hypertension is the most prevalent risk factor with a percentage of $85 \%$ which is similar to the study conducted by Lok $U$ et al [21] with the prevalence percentage of hypertension as $74 \%$ and A.Muscari et al [22] with the prevalence of $84 \%$. Diabetes is the second prevalent cause which was in lines with studies conducted by Lok $U$ et al [21], George J et al [23], and Maydadomac F et al [24]. Dyslipidemia being the least prevalent risk factor in the present study which is $33.7 \%$ is similar to the study by Muscari $A$ et al [22] which is $40.1 \%$. The laboratory findings showed that the leukocyte, neutrophil, lymphocyte, and platelet counts did not differ between these two groups of patients. There is no sign of these findings since it is almost similar in both groups with NIHSS $<6$ and those with NIHSS $>6$. In the present study, there is no sign of MPV concerning Stroke Score which is consistent with the study conducted by Al-Tameemi et al [25] but studies conducted by Butterworth et al [26], Ghahremanfard F et al [27] and Shah P et al [28] have shown significant raise in the MPV. There is also no significance of PDW in the present study which is consistent with the study conducted by AlTameemi et al [25] but a study conducted by; Shah $P$ et al [28] has shown significant raise in the PDW. Some studies have shown that there is an increase in these platelet indices in stroke patients in comparison to healthy patients but these indices are not significant to differentiate the stroke severity score. The present study showed a positive relationship between PLR and Stroke Severity Score. There is a significant rise in PLR in patients with NIHSS score $>6$ i.e., Group 2. This is consistent with a study conducted by Pei Hsun sung et al [29].

\section{Conclusion}

The present study has shown a significant difference in the values of PLR about Stroke Severity Score. Therefore, PLR is strongly related to the Stroke Severity Score thereby associated with the prognosis of the stroke.

\section{What does the study add to the existing knowledge}

There is no significant difference in MPV and PDW concerning Stroke Severity Score but these platelet indices can be used as biomarkers in stroke patients since there is a significant rise in these indices in stroke patients to healthy people.
It is also found that Hypertension is the most predominant risk factor among ischemic stroke patients.

\section{Author's contribution}

Dr. Dasari Govind: Concept, study design

Dr. Mallipeddi Malleswara Rao: Manuscript writing

Dr. K. Sudheer: Data analysis

\section{Reference}

01. Ga D, Fisher M, Macleod M, Davis SM. Stroke. Lancet. 2008;371(9624)1612-1623.

doi: $10.1016 /$ S0140-6736(08)60694-7 [Crossref]

02. Adams Jr HP, Del Zoppo G, Alberts MJ, Bhatt DL, Brass $L$, Furlan $A$, et al. Guidelines for the early management of adults with ischemic stroke- a guideline from the American Heart Association/American Stroke Association Stroke Council, Clinical Cardiology Council, Cardiovascular Radiology and Intervention Council, and the Atherosclerotic Peripheral Vascular Disease and Quality of Care Outcomes in Research Interdisciplinary Working Groupsthe American Academy of Neurology affirms the value of this guideline as an educational tool for neurologists. Stroke. 2007;38(5)1655-1711.
doi:
10.1161/CIRCULATIONAHA.107.181486

[Crossref]

03. D'Agostino RB, Wolf PA, Belanger AJ, Kannel WB. Stroke risk profile- adjustment for antihypertensive medication- The Framingham Study. Stroke. 1994;25(1)40-43.

doi: $10.1161 / 01$. str.25.1.40 [Crossref]

04. Ovbiagele B, Nguyen-Huynh MN. Stroke epidemiology- advancing our understanding of disease mechanism and therapy. Neurotherapeutics. 2011;8(3)319-329.

doi: $\quad 10.1007 / \mathrm{s} 13311-011-0053-1 \quad$ [Crossref]

05. Banerjee TK, Das SK. Fifty years of stroke researches in India. Ann Indian Acad Neurol. 2016;19(1)1-8.

doi: 10.4103/0972-2327.168631 [Crossref] 
06. Lloyd-Jones D, Adams R, Carnethon M, Simone GD, Ferguson TB, Flegal $K$, et al. Heart disease and stroke statistics 2009 update- a report from the American Heart Association statistics committee and stroke statistics subcommittee. Circulation. 2009;119(3)e21-181.

doi: $\quad$ 10.1161/CIRCULATIONAHA.108.191261

[Crossref]

07. Giovanetti T, Nascimento A. Platelet IndicesLaboratory and Clinical Applications. Revista Brasileira de Hematologia e Hemoterapia. $2011 ; 33(2) 164-165$.

doi: $10.5581 / 1516-8484.20110040$

[Crossref]

08. Pizzuli L, Yang A, Martin JF, Luderitz B. Changes in platelet size and count in unstable angina compared to stable angina and non-cardiac chest pain. Europe Heart J. 1998;19(1)80-84.

doi: 10.1053/euhj.1997.0747 [Crossref]

09. Bath PM, Butterworth RJ. Platelet sizemeasurement, physiology and vascular disease. Blood Coagul Fibrinolysis. 1996;7(2)157-161. [Crossref]

10. Enticknap JB, Gooding PG, Lansley TS, Avis PR. Platelet size and function in ischaemic heart disease. J Atheroscler Res. 1969;10(1)41-49.

doi: $10.1016 /$ S0368-1319(69)80080-3 [Crossref]

11. Jagroop IA, Mikhailidis DP. Mean platelet volume is an independent risk factor for myocardial infarction but not for coronary artery disease. Brit J Haematol. 2003;120(1)169-170.

doi: 10.1046/j.1365-2141.2003.03983_4.x [Crossref]

12. Dougherty Jr JH, Levy DE, Weksler BB. Platelet activation in acute cerebral ischaemia- Serial measurements of platelet function in cerebrovascular disease. The Lancet. 1977;309(8016)821-824.

doi: $10.1016 / s 0140-6736(77) 92774-x \quad$ [Crossref]

13. Toghi $H$, Suzuki $H$, Tamura K, Kimura B. Platelet volume, aggregation and ATP release in cerebral thrombosis. Stroke. 1991;22(1)17-21.

doi: 10.1161/01.str.22.1.17 [Crossref]

14. Smith NM, Pathansali R, Bath PM. Platelets and stroke. Vasc Med. 1999;4(3)165-172.

doi: $10.1177 / 1358836 \times 9900400307$ [Crossref]
15. Vagdatli, E, Gounari E, Lazaridou E, Katsibourlia E, Tsikopoulou F, Labrianou I. Platelet Distribution Width- A Simple, Practical and Specific Marker of Activation of Coagulation. Hippokratia. 2010;14(1)28-32.

[Crossref]

16. Kim JY, Park J, Chang JY, Kim SH, Lee JE. Inflammation after ischemic stroke: the role of leukocytes and glial cells. Experiment Neurobiol. $2016 ; 25(5) 241-251$.

doi: $10.5607 /$ en.2016.25.5.241 [Crossref]

17. Buck BH, Liebeskind DS, Saver JL, Bang OY, Yun SW, Starkman S, et al. Early neutrophilia is associated with volume of ischemic tissue in acute stroke. Stroke. 2008;39(2)355-360.

doi: 10.1161/STROKEAHA.107.490128 [Crossref]

18. Arbel Y, Birati EY, Finkelstein A, Halkin A, Berliner S, Katz BZ, et al. Red blood cell distribution width and 3-year outcome in patients undergoing cardiac catheterization. Journal of Thromb Thrombolysis. $2014 ; 37(4) 469-474$.

doi: $10.1007 / \mathrm{s} 11239-013-0964-2 \quad$ [Crossref]

19. Kasama T, Miwa $Y$, Isozaki T, Odai T, Adachi M, Kunkel SL. Neutrophil-derived cytokines potential therapeutic targets in inflammation. Curr Drug Targets-Inflammation Allerg. 2005;4(3)273-279.

doi: $10.2174 / 1568010054022114$ [Crossref]

20. Tekesin A, Tunç $A$. Inflammatory markers are beneficial in the early stages of cerebral venous thrombosis. Arquivos de Neuro-Psiquiatria. $2019 ; 77(2) 101-105$.

doi: $10.1590 / 0004-282 \times 20190001 \quad$ [Crossref]

21. Lok U, Gulacti U, Ekmekci B, Bulut T, Celik M. Predictive and prognostic role of mean platelet volume in patients with first-ever acute ischemic stroke. Neurosci. 2017;22(2)119-126.

doi: $10.17712 / n s j .2017 .2 .20160330$ [Crossref]

22. Muscari A, Puddu GM, Cenni A, Silvestri MG, Giuzio R, Rosati $M$, et al. Mean platelet volume (MPV) increase during acute non-lacunar isch emic strokes. Thromb Res. 2009;123(4)587-91. doi: 10.1016/j.thromres.2008.03.025 [Crossref] 
23. George J. A study on risk factors of patients with acute ischemic stroke at a tertiary care hospital. Int J Med Health Res. 2017;3(11)99101.

[Crossref]

24. Mayda-Domaç F, Misirli H, Yilmaz M. Prognostic role of mean platelet volume and platelet count in ischemic and hemorrhagic stroke. J Stroke Cerebrovasc Dis. 2010;19(1)66-72.

doi: $\quad 10.1016 / j . j s t r o k e c e r e b r o v a s d i s .2009 .03 .003$ [Crossref]

25. Al-Tameemi W, Ameen MM. Significance of Platelet Indices in Patients with Acute Ischemic Stroke. The Iraqui Journal of Agricultural Sci. 2012;10(4)383-389.

[Crossref]

26. Butterworth RJ, Bath PM. The relationship between mean platelet volume, stroke subtype and clinical outcome. Platelets. 1998;9(6)359364.

doi: $10.1080 / 09537109876429$ [Crossref]
27. Ghahremanfard F, Asghari N, Ghorbani R. The relationship between mean platelet volume and severity of acute ischemic brain stroke. Neurosci. 2013;18(2)147-151.

[Crossref]

28. Shah P, Mir R, Kamili M. Role of Mean Platelet Volume in Ischemic Stroke. JK Sci. 2013;15(3)136-139.

[Crossref]

29. Sung $\mathrm{PH}$, Chen $\mathrm{KH}$, Lin $\mathrm{HS}$, Chu $\mathrm{CH}$, Chiang JY, Yip HK. The correlation between severity of neurological impairment and left ventricular function in patients after acute ischemic stroke. J Clin Med. 2019;8(2)190.

doi: $10.3390 / j \mathrm{~cm} 8020190$ [Crossref] 